481

GASTROINTESTTINAL DISEASE AS AN INTEGRAL PART OF THE HEMOLYTIC UREMIC SYNDROME. Peter F. Whitington, Aaron L. Friedman, Russell $W$. Chesney, The University of a precursor of the Mus but Gastroenteritis is recognised as a precursor of the HUS but its role as major feature of this syndrome is less well established. The records of 12 patients, aged 1 to 40 years, in which a secure diagnosis of the HUS could be made on the basis of ac'ite axotemic renal failure with hemolytic anemia and thrombocytopenia were reviewed with respect to Gl desease. Gl complaints initiated the disease in all patients; 12 had bloody diarrhea, 8 vomited and 7 had cramping abdominal pain. These symptoms persis ted 2 days to 6 weeks before the diagnosis of the HUS was made. Prominent abdominal tenderness was elicited in 8 subjects, 2 had classical findings of peritonitis and 5 had hepatomegaly. Procto scopy, performed in 4 patients, revealed friable mucosa, 4 , lax anal sphincter tone, 2, a rectal ulceration, and a dirty gray pseudomembrane. Transaminases were elevated in all patients stud ied; SGOT and SGPT ranged from 58 to 468 and 89 to $149 \mathrm{IU} / \mathrm{L}$ respectively. Plain abdominal $x-r a y$ demonstrated ascites, 3 , mas sive colonic dilitation, 1 , and thumb printing of the sigmoid colon, 1, while barium enema, performed in 2 patients, showed ev idence of diffuse colitis, 2 , and a $2 \times 2 \mathrm{~cm}$. filling defect in th cecum. The illness was mistakenly diagnosed as appendicitis, ulcerative colitis, cecal polyp, pseudomembranous colitis or intersucception. An appendectomy and a colotomy were needlessly performed. All patients recovered normal Gl function with support for renal failure. We consider cal-liver disease to be a regular feature of the HUS

482 INTESTINAL MATURATION: EFFECT OF PREDNISOLONE ON 482 Univ. of Iowa coll. CALCIUM TRANSPORT. M. K. Younoszai and F. Ghishan,

In the aduit rat intestine, absorption of calcium (Ca) is decreased by administration of prednisolone in vitro but not in vivo. In suckling rats, serum corticol levels are low and intestinal absorption of calcium high, this provided an opportunity to investigate the effect of glucocorticoids in vivo. Test $(T)$ rats were injected with methylprednisolone, $5 \mathrm{mg} / \mathrm{kg} /$ day for 5 days prior to the studies and control (C) rats with the soivent. The jejunum + $i$ leum of anesthetized suckling (S) 14-15 day, weanling (W) 21-22 day and adolescent (A) 42 day $01 d, T$ and $C$ rats were perfused with isotonic $\mathrm{NaCl}$ solution containing $\mathrm{CaCl}_{2}(3.4$ nimoles /1), tracer ${ }^{45} \mathrm{Ca}$, and Phenol Red $(20 \mathrm{mg} / 1)$. Net absorption of calcium (NA of Ca) was measured under steady state conditions. Lumen to mucosa (LM) flux of Ca was estimated from absorption of ${ }^{45} \mathrm{Ca}$. In C rats, NA of Ca ( 4 moles $/ \mathrm{hr} / \mathrm{g}$. dry wt.) decreased significantly $(p<0.01)$ with age (Mean + S.E.; S, $23+4$; W, $14+2 ; A, 2+1)$. In $T$ rats, NA of Ca was similar in $-S$ and $W$ but significantly lower in A rats $(S, 13+3 ; W, 12+1, A, 2+$ 1). The LM fluxes in $C$ rats were: $S, 53 \mp 5 ; W, 26 \mp 4 ; A, 7 \mp$ $1 ;$ and in $T$ rats: $23 \pm 3,20 \pm 2$ and $7 \pm 1$. Thus, administration of methylprednisolone significantly reduced the NA of $C a$ and the $L M$ flux in $S$ but not in $W$ or $A$ rats. These results sugges ted that prednisolone decreased the permeability of the small intestine to $C a$ in $S$ but not in $W$ or $A$ rats. This effect could be tine to $\mathrm{Ca}$ in $\mathrm{S}$ but not in $\mathrm{W}$ or A rats. This effect
mediated through a Vitamin $\mathrm{D}$-independent mechanism.

\section{GENERAL PEDIATRICS}

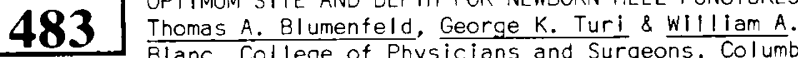

OPTIMUM SITE AND DEPTH FOR NEWBORN HEEL PUNCTURES. Blanc, College of Physicians and Surgeons, Columbia University, Departments of Pedi

Spon. By John Fick newborns have frequent heel punctures to obtain blood specimens for diagnostic tests. This study was performed to determine the optimum site and depth of these punctures. At autopsy both heels of 11 infants $<2 \mathrm{~kg}(\mathrm{Gp})$ and 12 infants $>2-5 \mathrm{~kg}(\mathrm{Gp} 2)$ were examined. On a line between the lst and 2nd toes an incision was made in the heel and the depths from the skin surface to the upper subcutaneous tissue $(S-S)$, where the larger blood vessels are present, and from the ski- surface to the periosteum (S-P) were measured $4:$, h a caliper. In GP1 the $\bar{x} S-S$ was $0.67 \mathrm{~mm}(0.5-0.8)$ and the $\bar{x} S-P$ was $4.5 \mathrm{~mm}$ (3.6$5.6)$ and in Gp2 these measurements were $1.0 \mathrm{~mm}(0.7-1.4)$ and $6.0 \mathrm{~mm}(5.0-8.4)$. The calcaneus did not extend beneath the plantar surface at the level of the 5 th toe and the $5-P$ depth was less at the posterlor portion than at the midportion of the healing Histological examicro abcesses and perichondritis, and healing and scaring, micro abcesses and perichondrium.

We conclude that newborn heel punctures should be performed

We conclude that newborn heel punctures should be performed
on the lateral plantar surface at the level of the 5 th toe and if the infant is $\overline{2} 2 \mathrm{~kg}$ the depth should be $1.0-3.0 \mathrm{~mm}$ and if the infant is $>2-5 \mathrm{~kg}$ the depth should be $2 \cdot 0-4.0 \mathrm{~mm}$ to avold bone puncture.
484

EVALUATION OF A REGIONAL PERINATAL EDUCATION PROGRAM FOR HEALTH PROFESSIONALS. Robert C. Borer, Jr., William R. Harlan, Roland G. Hiss, James V. Griesen, Jan Schneider, George E. Hess, Barbara S. Rothfeder, Pamela A. Giering Spon. by Will iam J. 0liver), Univ. of Mich. Sch. of Med., Ann Arbor.

A modular, self-paced instructional program in neonatal respiratory distress was provided to all levels of health professionals and evaluated for its ability to cause cognitive change. The program consisted of 30 media packages (video-tape and slide tape) and a study guide. Local hospital personnel in 3 communities were responsible for dissemination of the program to 187 potential participants. $63 \%$ of the MD's, $73 \%$ of the RN's and $64 \%$ of the LPN's completed eight or more of the packages. Cognitive change was assessed by written tests administered before and following presentation of the study materials in the community hospitals.

\begin{tabular}{crcrcr} 
Learner & $n$ & Pretest Score & SD & Post-test Score & SD \\
\hline MD & 27 & $58 \%$ & 9 & $76 \%$ & 11 \\
RN & 65 & $56 \%$ & 8 & $73 \%$ & 10 \\
LPN & 23 & $49 \%$ & 7 & $67 \%$ & 9
\end{tabular}

All professional groups demonstrated a gain in cognitive leve Score differences between pediatricians and obstetricians on pediatric care and obstetric care were significant $(p<.05)$ in the pretest but no differences were found in the post-test. This community-based educational program was effective in increasing the cognitive level of learners representing wide differences in professional background. Changes in care were documented in the hospitals as a resuit of this program.

485 A FAILURE IN MEDICAL AND RESIDENT EDUCATION: THE 485 UNSCRUPULOUS EXPERT WITNESS. Robert L. Brent, University, Department of Pediatrics, Phila., Pa.

The exponential increase in malpractice suits and medical negligence litigation has brought an increasing number of physicians into the courtroom as expert witnesses for the plaintiffs and the defense. Analysis of the testimony reveals that medical expert witnesses are frequently confused about their role in court. This confusion occurs for several reasons. Medical students and residents are given no organized or scholarly exposure to the courtroom. Experts frequently believe that they should be active participants in winning a case. Taking on this inappropriate role frequently results in dishonesty and lack of scholarship. The financial remuneration for expert witnesses has reached a level that has made it an attractive area for unscrupulous professional witnesses. It is essential that the quality and accuracy of expert testimony be improved. Although major changes in the judicial process could correct many aspects of this problem, it is unlikely to be forthcoming. The most immediate solution would be to publicize the testimony of expert witnesses so that the entire medical profession can scrutinize the level of an expert witness 'scholarship. (HD 630; HD 7075; HD 11038)

\section{6}

ROLE CONCEPTS AS PREDICTORS OF RESIDENTS' PERFORMANCE Recent work (Cook relationship $(r=.47)$ between a physician's moral reasoning and the quality of clinical performance. To extend these studies of non-cognitive abilities a standardized interview was conducted with 100 residents in Pediatrics and Medicine, focusing on the doctor-patient relationship. Each subject's interview was scored blind (i.e., without knowledge of the subject's responses to other questions or of his performance rating). Responses were analyzed according to a fully defined 40-category scoring system. A Role Concept Index was computed using those categories which, on the basis of theory and pilot research, were expected to distinguish good from poor physicians. Clinical performance was independently rated by faculty on a 7 -point scale. To date, 26 interviews have been analyzed. Initial results show a correlation of .41 ( $p<.05)$ between the Role Concept Index and overall performance. In particular, superior residents are distinguished in 15 role concept categories including the following: 1) roletaking ability (seeing the patient's problem from the patient's perspective), 2) encouragement of patients' participation in their management, 3) knowing one's own limits, 4) willingness to take responsibility, 5) willingness to make personal sacrifices, and 6) ability to prevent personal problems from interfering with patient care. The usefulness of the Role Concept Index in predicting clinical performance suggests its inclusion among criteria for residents' selection and evaluation. 